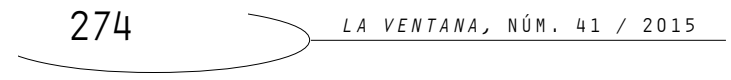

\title{
De la ideología a la identidad en mujeres con cáncer cervicouterino
}

\section{Ma. del Carmen Calderón Benavides*}

* Unidad de Tumores Ginecológicos del Servicio de Oncología del Hospital General de México. País: México. Correo electrónico: marycarb@unam.mx

RECEPCIÓN: 14 DE MARZO DE 2013 / ACEPTACIÓN: 18 DE MARZO DE 2015

\section{Resumen}

El trabajo expone cómo las mujeres participantes crecieron y formaron parte de un contexto enmarcado en condiciones socioeconómicas, culturales y simbólicas que propició la integración a sí mismas de los procesos ideológicos contenidos en la vida diaria, dando paso a la formación de la identidad: el concepto de yo soy, desde donde han vivido lo culturalmente lícito y se han convertido en mujeres enfermas de cáncer cervicouterino. Las participantes fueron quince mujeres de entre $36 \mathrm{y}$ 48 años de edad, que acudieron a atenderse por cáncer cervicouterino. Aspectos significativos fueron: la relación con sus padres, la calidad y características de sus vínculos y el lugar que ocuparon en la familia.

Palabras clave: ideología, identidad, cuerpo, mujer, cáncer cervicouterino.

\footnotetext{
Abstract

This work exposes how the participating women grew and formed part of a context framed in socio-economic, cultural and symbolic conditions REVISTA ESTUDIOS DE GÉNERO. LA VENTANA, NÚM. 41, ENERO-JUNIO DE 2015, PP. 274-306, ISSN 1405-9436
} 
which led to the integration of themselves in the ideological processes of everyday life, giving way to the formation of the identity: the concept of "I am", where they have lived as culturally fair and they have become women suffering from cervical cancer. Participants were 15 women aged between 36 and 48, who came in for cervical cancer. Significant aspects were the relationship with their parents, the quality and characteristics of their bonds and the place they occupied in the family.

Keywords: ideology, identity, body, female, cervical cancer.

\section{El cáncer cervicouterino es un problema de salud pública} en México; se trata de la segunda causa de muerte entre las mujeres de 35 a 45 años de edad. Cada año mueren aproximadamente 4500 mujeres y son registrados alrededor de 15000 nuevos casos. En el año 2011, se reportaron 2462 fallecimientos. Aun cuando se trata de una enfermedad tanto prevenible como curable, muere una mujer en etapa productiva cada dos horas desde hace veinte años (Torres, 2010).

El análisis del problema que implica el control de la enfermedad, se dirige hacia los programas establecidos, que no han funcionado como se esperaba, pues la experiencia en otros países ha demostrado que:

La mejor opción para disminuir la mortalidad por cáncer cervicouterino es la detección y el tratamiento de lesiones precursoras y malignas, por medio de programas de detección 
oportuna. Aunque existe un programa nacional de Detección Oportuna del Cáncer (DOC), mediante la prueba de Papanicolaou (Pap), desde 1974 en México, el cáncer cervicouterino sigue siendo una de las principales causas de muerte para las mujeres mexicanas. En nuestro país ha sido difícil establecer y mantener un programa de tamizaje efectivo, tal como los programas de los países desarrollados, que sí han logrado disminuir sus tasas de mortalidad (Hidalgo, 2006: 81-82).

Estos datos reflejan que el procedimiento con el que se ha afrontado al cáncer cervicouterino no ha sido el más adecuado, y que hay que intentar descubrir cuáles son las dificultades y las carencias que han obstaculizado una apropiada aplicación de los programas dirigidos a esta enfermedad.

Es necesario reconocer la existencia de factores sociales, psicológicos y antropológicos que dificultan la prevención y el tratamiento oportunos del cáncer cervicouterino (Careaga, 1998), como la vivencia del cuerpo de las mujeres y la localización de la enfermedad, pues al ubicarse en el aparato sexual reproductor vincula a la vida sexual activa y a la sexualidad, que no es el sinónimo de relaciones coitales, sino el conjunto de fenómenos y sucesos biopsicosociales que, a lo largo de la vida, definen el comportamiento del individuo con los demás seres humanos que lo rodean, según su autopercepción de hombre o mujer y según su preferencia sexual, y que por lo tanto se manifiesta y está presente en todos los momen- 
tos, en los distintos ámbitos y a lo largo de todo el ciclo de la vida de las mujeres y de los hombres (Allen, 1998).

Un aspecto primordial en el enfermar es el género. Los roles de género influyen en el proceso salud-enfermedad de los hombres y de las mujeres: la cultura construye a sus integrantes asignándoles características mediante la enseñanza de actitudes y conductas deseables al contexto histórico, geográfico e ideológico, encaminado a reproducir y garantizar la preservación de la sociedad. Con esta transmisión generacional, se construye un individuo social con un estilo y calidad de vida: una vida cotidiana que contiene la reproducción de los factores de riesgo de los modos de enfermar.

Los factores de riesgo del cáncer cervicouterino forman parte del estilo de vida, provienen de la ideología cultural que se encarga de la formación de los sujetos: el inicio prematuro de la vida sexual activa, la promiscuidad sexual, embarazos en edad temprana, infecciones frecuentes, tabaquismo, deficiencias nutricionales, son acontecimientos que forman parte de un contexto con toda una serie de características, al que es necesario estudiar para profundizar en el conocimiento de las condiciones de riesgo.

De acuerdo con Lagarde:

Los procesos de cada mujer a lo largo de su biografía y en su cotidianidad, permiten conocer, explicar y comprender el estado de su salud. Las dificultades y los conflictos, las enfermedades, los accidentes y las carencias, las maneras de enfrentarlos, así como los logros, las actividades enriquece- 
doras, la ausencia de malestares y de enfermedades o daños y el disfrute de la vida, se plasman en el cuerpo y la subjetividad, en el cuerpo vivido y producen un específico estado de salud definitorio del estado vital con que cada mujer enfrenta su existencia (Lagarde, 1997: 28).

El enfoque de género aplicado al estudio de la salud de la mujer dirige la atención hacia el análisis de las relaciones entre la biología y el medio social, que se plasma en situaciones de desventaja o ventaja de las mujeres frente a los hombres, desigualdad entendida en términos de las probabilidades de gozar de salud, de enfermar o de morir.

\section{Cuerpo e Ideología: la transmisión cultural a través de la familia}

Al nacer un ser humano, la construcción de su realidad se establece en el plano de la experiencia que le da el sentir, la formación del yo corporal tiene como base el desarrollo del principio de la realidad, que consiste en un proceso de diferenciación: el bebé establece los límites entre él y su madre, reconoce que son dos personas diferentes, pero además enfrenta las sensaciones desagradables y la necesidad de satisfacerlas. En esta etapa del desarrollo humano es especialmente significativa la relación madre-hijo, que genera una comunicación a través del cuidado materno hacia las necesidades primarias del niño, una comunicación corporal, gestual y actitudinal 
que forma parte del estilo de crianza aprendido tradicionalmente y que es definido por cada cultura. Mucho de esa transmisión cultural se da en el plano del sentir a la madre y traducir el mensaje que la comunicación materna le emite, con gestos, tonos de voz: "el componente de la emoción materna se transmite de cuerpo a cuerpo; con el contacto de un cuerpo emocionado que toca al nuestro, una mano que nos toca sin placer no provoca la misma sensación que una mano que siente placer al tocarnos" (Aulagnier, 1991: 152).

Este estilo de crianza basado en la comunicación corporal es el encargado de la transmisión básica de la cultura, más allá de manifestaciones verbales, el niño aprende con su cuerpo y del cuerpo de los otros, de la emoción transmitida, de la percepción de su propio cuerpo y de su expresión emocional.

Al respecto, Bordieu menciona:

Lo que se aprende por el cuerpo no es algo que se posee, es algo que se es. El mundo de los objetos, esta especie de libro donde todas las cosas hablan metafóricamente de todas las demás y en el que los niños aprenden a leer el mundo, se lee con todo el cuerpo (Bordieu, en Islas H., 2001: 143).

De esta manera, el orden social va reproduciendo los imperativos culturales en la incipiente personalidad del recién nacido, quien aprende a identificar sus emociones y las de los otros a partir del contacto y de la observación. El bebé es atento a los mensajes corporales de la madre como: su tono de voz, su temperatura y su res- 
piración, mismos que le dirán lo que él representa para ella. La calidad afectiva y emocional que ella le imprima a los cuidados que le brinda son captados por él, quien adquiere o no la nutrición afectiva suficiente y necesaria que es determinante para su formación y solidez interna.

Así, este nuevo ser aprende quién es a partir de lo que es para los otros y de lo que observa que esos otros son para sí mismos, a lo que se denomina "visión de espejo". Se inicia el proceso de formación de identidad, basado en la construcción de la imagen corporal para la que son de enorme importancia, de acuerdo con Schilder (1989), los contactos con los demás, el interés que ellos manifiesten por las distintas partes de nuestro cuerpo, así como lo que hacen con su cuerpo, porque la imagen corporal la construimos sobre la base de los contactos sociales. La imagen corporal es elaborada a través de las experiencias de las acciones y actitudes de los demás dirigidas al cuerpo del niño o hacia su propio cuerpo. "La relación con la madre es fundamental, si ella permanece ciega o sorda a lo que le ocurre al cuerpo del niño, se movilizarán defensas y se modificará la relación con la imagen del propio cuerpo y de sí mismo" (Fernández-Ruíz, 1999: 67).

Para Aulagnier (1991) todo niño acude a ocupar un sitio en el mito familiar, que será lo que lo constituirá como sujeto, la confianza en sí mismo es adquirida a partir del contacto con las personas significativas de su vida, su madre o quien desempeñe el rol materno, ese contacto le hace posible resistir las variaciones y las amena- 
zas del medio. La construcción de su identidad se establece encontrando su lugar en la familia.

\section{Ideología e Identidad}

La interacción con un mundo poblado de seres humanos donde la observación y el reconocimiento mutuo son acontecimientos cotidianos, es lo que hace posible el desarrollo del proceso de identidad, haciendo referencia a la historia y a la reproducción cultural. La identidad es el resultado de la incorporación del proceso ideológico que se transmite generacionalmente para garantizar la permanencia de la cultura, pues a partir de la ideología, el individuo se convierte en sujeto, al reproducir estructuras de significados. Se lleva a cabo a partir de la pertenencia a una comunidad que cuenta con un sistema de valores, de creencias, de acciones significadas, de prácticas sociales que incluyen actos y objetos con sentido, donde se llevan a cabo prácticas cargadas de significado. Poseer una identidad significa haber integrado al sí mismo los procesos ideológicos y ser capaz de reproducir las prácticas con sus significados, percibir la realidad unida al sentido que le ha dado la ideología de su contexto (Aguado, 2004).

La cultura nos deposita sus valores en el cuerpo, nuestra percepción de los acontecimientos y de los fenómenos que nos rodean, está determinada por este filtro, y una vez integrado da paso a la individuación, que es la manifestación de la reproducción cultural elaborada plenamente. De esta manera, la cultura construye seres 
humanos ideológicamente sujetos y capaces de producir y reproducir prácticas que garantizan a su vez, la reproducción del sentido. La identidad individual forma parte de la identidad colectiva.

Desde la perspectiva de la cultura, la ideología es el proceso que da sustento a la producción, reproducción y reestructuración del sentido, dentro del concepto de realidad, se revisa el concepto de apropiación cultural de esa realidad que se denomina experiencia humana (Ibídem: 38).

Culturalmente definida, la ideología hace posible la conservación del sistema de creencias y de representaciones, y en una dinámica de acción permanente, mantiene la identidad.

La ideología es un proceso que se ocupa de definir al sujeto en y para la acción. La conducta humana se caracteriza por estar incluida siempre en un espacio de significación social denominado contexto cultural, que es el conjunto de referentes simbólicos que definen a un pueblo y que contienen las posibilidades de acción del mismo. Es un conjunto de posibilidades de acción en un momento determinado (tiempo) y en un contexto específico (espacio) (Ibídem: 40).

La cultura se inscribe en el cuerpo a través de la transmisión ideológica y da paso a una identidad que se convierte en un yo soy, donde la primera certeza es precisamente la posesión de un cuerpo, 
que es siempre la expresión de ese yo perteneciente a un mundo, pues desde el cuerpo se establece la existencia donde cuerpo y yo somos lo mismo: yo soy mi cuerpo, mi yo, mi identidad.

El proceso de integración de la identidad se da por igual en los seres humanos; es decir, se inicia con el nacimiento, pero la diferencia anatómica: ser hombre o ser mujer, determina la ideología que le será transmitida al bebé para la reproducción cultural del género femenino y del género masculino.

La identidad de género es precisamente esa carga de significados que se asignan a un cuerpo de hombre y a un cuerpo de mujer; se convierte en una experiencia privada del rol de género como expresión pública de identidad, una red de creencias, rasgos de personalidad, actitudes, valores conductas y actividades que distinguen al hombre y a la mujer. La identidad de género son modos de pensar, de sentir y de comportarse que se transmiten ideológicamente y que son incorporadas y configuradas psíquica y socialmente como masculino y femenino. De acuerdo con Martha Lamas, la identidad de género es la interiorización de rasgos subjetivos de un ideal social que pasa a ser constitutivo de su definición como sujetos, que se configuran como rasgos de carácter naturales a la masculinidad y feminidad (Lamas, 1996).

La asignación de la identidad de género ha sido condicionada por el momento histórico y por la ubicación que la familia y el entorno le dan a una persona a partir de la simbolización cultural de la diferencia sexual. 
La organización social asimétrica en la que la división sexual del trabajo ha establecido las jerarquías del hombre y la mujer, produce y reproduce identidades diferenciales y desiguales, porque la construcción de la identidad de género se basa en la división sexual del trabajo, en la que la opción público-privado es un eje estructural que articula las concepciones ideológicas de lo masculino y de lo femenino. Las identidades de género han sido construidas para favorecer un sentimiento compartido de pertenencia e identificación.

Porque como indica T. Laqueur (1994) "ser hombre o mujer significa tener un rango social, un lugar en la sociedad, asumir un rol cultural, tener una categoría sociológica".

\section{El cuerpo de la niña y su madre}

La relación con la madre ha sido establecida como la más importante en nuestra cultura, la figura materna es la que se encarga de transmitir a la hija el sistema ideológico con sus creencias, mitos y estereotipos que configurarán a un ser humano con cuerpo de mujer, con anhelos, sentimientos, pensamientos y comportamientos femeninos, siendo ella, la madre, el modelo a seguir mediante el proceso de identificación.

Existen condiciones que en este proceso de identificación, propician que la madre manifieste únicamente los factores de satisfacción y plenitud contenidos en el ejercicio de la maternidad, convirtiéndola en un mito; por ejemplo: cuando se encuentra de- 
dicada en exclusiva a su rol materno, sin desarrollar una identidad en otros ámbitos, se generan vacíos de comunicación relacionados sobre todo con la sexualidad, al tener dificultad para aceptar a sus hijas como seres sexuales y se fomenta esa realidad disfrazada del ser madre ocultando las emociones negativas que surgen con ella (González, 1993).

La ambivalencia presente en toda relación madre-hija, unida a todos los silencios (la prohibición de hablar) maternos en torno a la realidad de las propias vivencias que de ser expresadas, develarían la falacia de la inmensa felicidad y plenitud ( $\sin$ la soledad, angustias, sacrificios, etc.) que caracterizan la experiencia de la maternidad para la mujeres, genera que el modelo materno, quede internalizado sin fisuras y convertido en estructura psíquica a través del proceso de identificación mediante el cual muchas de las normas maternas son interiorizadas bajo un ideal del yo que ha sido denominado ideal materno (Op. cit.: 84).

Este ideal materno se convertirá en el rector de todas las conductas de las mujeres, pues la maternidad es convertida en la base de la identidad femenina, un rol que exige la eliminación de sí misma de todo aquello que sea para sí: egoísmo, erotismo, hostilidad, necesidad de apoyo, de descanso, de cuidados, etc., dando paso a una culpabilidad constante que rige su vida ante el deber de ser una excelente madre, carente de sí; y da inicio a un ejercicio 
mistificado del ser madre, ser para los otros, sin otras fuentes de satisfacción. La mujer mide su propio valor a través de la responsabilidad y el cuidado que tiene a su cargo y define su sentido de identidad de acuerdo con la relación que mantiene con otros individuos (Abelin, 1999).

En la mística de la maternidad se configura la imagen que establece a la maternidad como la esencia de la feminidad y del ser mujer; y se convierte en una prescripción, en un mandato social que la mujer antepone a todo: de ahí proviene, entre otros, el miedo al éxito, porque la ambivalencia y la culpabilidad se instalaron en los intentos de autoafirmarse fuera del rol materno.

Las vivencias femeninas en todo lo relacionado con la sexualidad y el propio cuerpo también se constituyen en aspectos antagónicos a la maternidad. "Y a pesar de que se insista en el valor narcisístico que la mujer concede a su cuerpo, no puede decirse lo mismo de cómo vivencia sus órganos genitales" (González, 1993: 109).

Los órganos genitales, entre ellos y quizás sobre todos: la vagina, esa parte del cuerpo femenino que ha padecido la invisibilidad: "no se ve", la anestesia: "no se siente", el silencio: "de eso no se habla", el estigma: "es malo", la negación: "no se toca". Un órgano que ha producido nerviosismo y angustias, y todo tipo de tabúes:

La idea del cuerpo femenino en su profundidad, la idea de la vagina, se funda en la oscuridad de su conformación. En la historia de la medicina, la anatomía ha dudado mucho antes de adentrarse más allá de los labios vaginales, mientras las 
restantes partes del cuerpo humano eran seccionadas, escrutadas y analizadas. Los tabúes que siempre han extendido su red inhibitoria sobre la anatomía sexual femenina, han permanecido vigentes en la ciencia médica (Leonelli 1995: 18-19).

Es la actitud del silencio que manifiestan las mujeres que son atendidas de cáncer cervicouterino, y que están relacionadas con las funciones de su aparato sexual reproductor, pues aun habiendo presentado síntomas en una etapa que haría posible la detección oportuna, los ignoran y guardan silencio ante ellos, a pesar de contar con la información suficiente respecto a los métodos de detección y aunque los síntomas sean graves y crónicos: "no los ven, no los tocan, no los sienten, no los dicen, son malos", dejando pasar el tiempo porque todo lo que les pasa "ahí, en mi parte" lo viven como que "es normal y se quita solo, no se dice porque da pena, es como confesar que andan de locas"; al respecto Leonelli menciona:

El conocimiento de la vagina, tal como es fisiológicamente, no influye ni modifica la idea o la imagen de cómo un hombre o una mujer piensan o viven la vagina. Hombres y mujeres se sienten turbados y reaccionan con sarcasmo. El silencio impuesto por las reglas de educación, por el "de esto no se habla", "no se siente", "no se mira", "no se mueve", "no se toca" es la respuesta más extendida y rápida, la ansiedad aumenta y "de esto no se habla" ni siquiera con uno mismo (Leonelli, 1995: 211). 
Y agrega:

Demasiadas mujeres mueren debido a enfermedades que atacan órganos que ellas han ignorado, prácticamente durante toda su vida: el cuello del útero, la vulva, la vagina y el útero, con un diagnóstico tardío provocado por un oscurantismo, convertido en pudor (Op. cit: 75).

La concepción del cuerpo se construye a través de la familia y los mensajes que recibimos referentes a nuestro cuerpo, a nuestros genitales, influyen profundamente en nuestra identidad y en la percepción de nosotros mismos:

Las vicisitudes del cuerpo son algo que se construye a través de la novela familiar y una libidinización que lo convierte de cuerpo biológico en cuerpo erógeno, significado fundamentalmente por los progenitores, pero también por la sociedad y sus imaginarios. La historia del cuerpo tiene que ver con una historia personal y con una historia social, diálogo que el sujeto establece consigo mismo y con los otros y que le permite ir construyendo una identidad (Fernández-Ruíz, 1999: 63).

Dejours (1992) se refiere al tema del cuerpo biológico y cuerpo erógeno y menciona que el desarrollo del cuerpo erógeno es el resultado de un diálogo en torno al cuerpo y sus funciones, que se apoya en los cuidados corporales prodigados por los padres y cuyas 
etapas se encuentran en los primeros años de vida, que resultan determinantes para la construcción de la identidad y la significación del sí mismo basada en el cuerpo. De igual forma, la relación con la madre, puesta de relieve en la construcción del vínculo de la hija consigo misma a través de su cuerpo, concebido, recibido y significado por ella; y que a través del cual, se generará una historia y una manera de ver y vivir el mundo.

\section{Método}

El planteamiento metodológico se establece desde el enfoque de la salud reproductiva y de las ciencias sociales. Como un trabajo realizado desde la historia de mujeres con cáncer cervicouterino, se trata de un enfoque que permite la revelación de sí mismas, de conocer sus puntos de vista ante los acontecimientos relacionados con la enfermedad y su participación en ellos, sus opiniones, sus emociones y sus percepciones. La reconstrucción de su vida desde la narración permite rescatar su visión de la realidad, de acuerdo con Plummer (1989) establecemos que "la historia personal revela, como ninguna otra cosa puede hacerlo, el reino de lo subjetivo" (citado en Lau, 1994: 95).

Remitirnos a los antecedentes de las mujeres con cáncer cervicouterino tiene como objetivo visualizar el contexto de la mujer y la importancia que puede tener para el desarrollo de la enfermedad. 


\section{Diseño de investigación}

Con el propósito de profundizar en el estudio de los mecanismos que intervienen y descubrir cuáles pueden ser las dificultades y las carencias que han obstaculizado una apropiada aplicación de los programas dirigidos a la detección oportuna del cáncer cervicouterino, se desarrolló un diseño etnográfico de investigación cualitativa en el que fueron entrevistadas individualmente 15 mujeres de edades entre los 37 y 48 años, con diagnóstico de cáncer cervicouterino en etapa de vigilancia, y que fueron tratadas mediante cirugía, radioterapia y quimioterapia.

Para la recopilación del material de estudio fue utilizada una entrevista a profundidad semiestructurada, cuya concepción fue el resultado del trabajo realizado en el área de tumores ginecológicos y de la observación participante. La entrevista incluye aspectos relacionados con la historia de vida de las participantes: su infancia, su desarrollo, sus vínculos afectivos, la dinámica familiar, los discursos dominantes y la influencia en la integración de su subjetividad y su toma de decisiones.

Se realizó análisis de contenido elaborando la categorización referente a la situación, contexto, actitud, comportamientos, sentimientos y opiniones del proceso de la enfermedad. Las entrevistas se llevaron a cabo en el aula del Servicio de Oncología. Les fue explicado con detalle el objetivo de la entrevista, se respondieron todas sus dudas y se solicitó firmar el consentimiento informado, en el que se requirió de su autorización para grabar y transcribir los 
contenidos de las sesiones, haciendo énfasis en el respeto hacia el anonimato y el manejo ético de los datos personales.

El objetivo consistió en determinar las características de los antecedentes familiares de las entrevistadas, la transmisión ideológica y la formación de la identidad, así como describir y analizar la vivencia corporal previa al desarrollo del cáncer cervicouterino.

Debido a que el proceso adaptativo ante la pérdida de la salud por cáncer atraviesa por las etapas de diagnóstico, tratamiento y vigilancia. Haber superado la etapa de tratamiento es fundamental para la recuperación física y emocional de las personas enfermas de cáncer, quienes en ese momento se inician en la etapa de vigilancia y de rehabilitación, y se encuentran en posibilidades de reintegrarse y recuperar su vida cotidiana, dejando atrás los efectos secundarios de los tratamientos. Es la razón por la cual la etapa de vigilancia fue un criterio de inclusión para las mujeres de este estudio.

La selección de las quince mujeres participantes se realizó durante la consulta externa que se lleva a cabo diariamente en la Unidad de Tumores Ginecológicos del Servicio de Oncología del Hospital General de México (ver Tabla 1).

\section{Resultados}

Se ha elaborado un análisis de las relaciones familiares de las participantes y del contexto que rodeó su infancia para identificar las condiciones familiares, sociales y culturales que antecedieron el desarrollo del cáncer cervicouterino. 


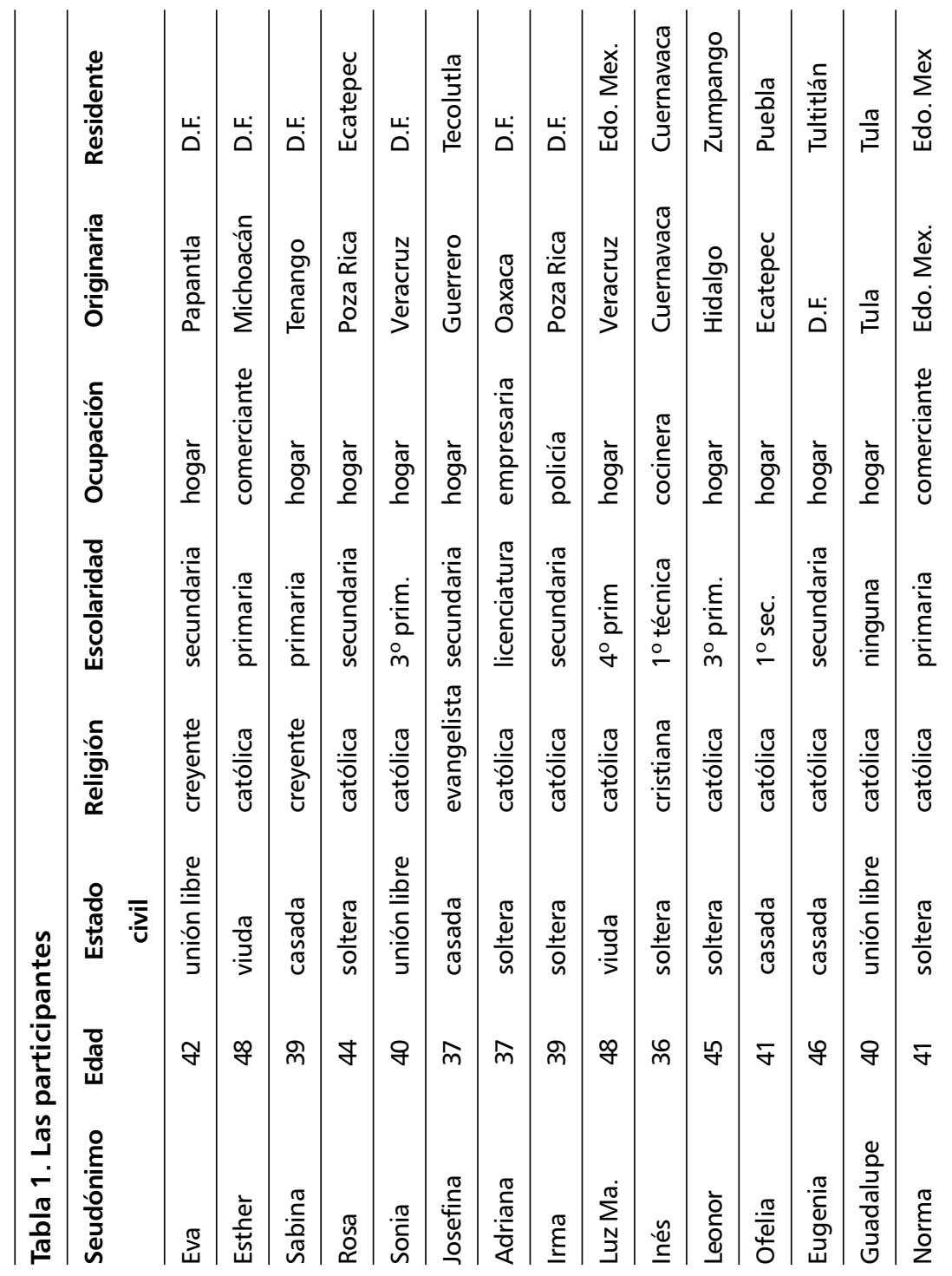


A decir de González (1993) se trata de integrar los diversos enfoques con que se ha estudiado la problemática de la mujer con el propósito de contextualizar la formación de la identidad femenina en el conjunto de condiciones socioeconómicas, políticas, culturales y simbólicas que la enmarcan, la información obtenida en diversos estudios de las ciencias sociales permite trazar una línea explicativa de los modos de enfermar de las mujeres.

Las participantes fueron socializadas en un entorno cultural rural y urbano marginal, son de baja escolaridad y crecieron en condiciones de pobreza. Fueron niñas pertenecientes a familias numerosas y disfuncionales, debido a la conflictiva relación de pareja de sus padres.

Los aspectos relacionados con las vivencias que tuvieron de niñas, su ambiente familiar, la relación con su cuerpo y consigo mismas indican las condiciones de precariedad y maltrato que rodea su desarrollo, la frustración ante el deseo de ir a la escuela, de vivir como niñas y no como sujetos de explotación laboral a la que se vieron sometidas por las condiciones familiares y por la extrema pobreza.

Se detectaron características comunes en las historias de las mujeres participantes: en la familia de origen destaca de manera importante la figura de la madre.

\section{Relación madre-hija}

En la relación con la figura materna que refieren las mujeres entrevistadas predomina la privación afectiva y una infancia con carencias. Hubo una constante en la ausencia del contacto físico. 
No me gustó cómo era mi mamá, no porque ella (llora) nunca nos acarició, mi mamá nunca me acarició, nunca me dijo si me quería o no me quería, nunca me dio un abrazo, un beso, no, yo siempre la quise así y yo trabajaba y todo lo que ganaba se lo daba y siempre sentía que no era suficiente lo que le daba, Eva no era una mamá que dijera icómo estás, cómo sientes? O iqué te pasa? Yo no sé lo que es amor de mamá, nunca sentí que me quería. Sonia

Muy, muy distante, mi mamá era muy agresiva conmigo, era a la que más me pegaba. Me da dolor, me da dolor. Inés

El trabajo y la explotación infantil se combinan con la indiferencia hacia los sentimientos y deseos de las niñas que, sin embargo, desarrollan generosidad y aceptan el sacrificio, en una manifestación contraria (iencubierta?) a la expresión abierta de la hostilidad que la frustración les produce:

Todo lo que ganaba se lo daba y siempre sentía que no era suficiente lo que le daba... Trabajé desde chiquita, los doce años, nueve, nosotros siempre trabajamos, desde los tres años nos llevaban al rancho a traer maíz. Eva

Mi mamá nos pegaba, nos mandaba a vender tamales, enchiladas y que si no vendíamos no nos daba de comer. Un rato íbamos a vender y al otro rato íbamos para la escuela. Si 
nos mandaron a la escuela, yo dejé de estudiar cuando mi papá se dejó de mi mamá, porque mi mamá me puso trabajar a luego. Sonia

Mi mamá tenía una creencia en cierta forma que, que me destruyó mi infancia. Ella decía que yo tenía don para curar, entonces mi mamá me sacó de la escuela para que me dedicara a curar, pero pues yo no, yo era una niña tonta, bien tonta, pero lo que decía mi mamá es lo que se hacía.

Me sacó de la escuela para eso, para que no me distrajera yo, para que me dedicara únicamente a eso, pero yo no sabía de nada, lo que me decían era lo que yo hacía y me mandó a vivir con un tío que era el que curaba y que según él me iba a enseñar y que no sé qué, yo tenía nueve años, no veía yo a mis papás desde que me fueron a dejar ahí, yo dije pues es que esto no, esto no es para mí, yo quería ser una niña que todavía jugaba.

No sentía nada, y llegó, pasó el tiempo y que yo no alcanzaba a ver cosas, yo no alcanzaba a ver nada, no. Y fue por eso que, que mi tío dijo que yo no estaba, que yo no me quería preparar y como que, se quejó con mi mamá. Y mi mamá se enojó mucho y yo no, que yo no ponía nada de mi parte y no sé qué. Ya mi mamá me llevó para la casa otra vez, después de un año.

Y ya ahí estuve en la casa, ahí estuve en la casa, que nos ponía que a hacer las tortillas, que a lavar los trastes, quehacer de la casa, a cuidar a los hermanitos. Leonor 


\section{Relación padre-hija}

La ausencia paterna es el factor que se distingue en la relación de las mujeres entrevistadas, con sus padres ausentes, distantes e indiferentes. El resentimiento y el coraje ante la figura paterna, son los sentimientos expresados, describen a un hombre sin el menor interés hacia sus necesidades de niñas. De las quince mujeres participantes, trece describen a un padre violento, autoritario, alcohólico y promiscuo.

Fernández menciona que: "las descripciones más frecuentes de los diversos autores en torno a la figura paterna de la mujer masoquista, son el padre autoritario o sádico y las del padre ausente" (1993: 97).

Mi papá nomás nos decía que nos quería pero él no hacía nada por nosotros. Eva

Mi papá, pus siempre fue de trabajar y trabajar, y él sólo lo veíamos sábado y domingo que eran los días que estaba con nosotros, trabajaba en el Estado de México, en Zumpango, ahí siempre ha trabajado, entonces él salía los lunes y regresaba los sábados. Era papá de fin de semana. Guadalupe 


\section{Frustración}

La frustración es otro elemento significativo en las historias, al serles asignados roles y delegar en ellas responsabilidades inadecuadas para su edad.

Yo quería ser una niña que todavía jugaba. Mi mamá dijo: tú no vas a la escuela, tú vas a la cocina. Total si a ti te van a mantener. Le dije: pero si yo quiero ir a la escuela, — tú no vas a ir a ninguna parte, aquí en la cocina, a aprender a hacer tortillas, la comida-. Pero yo siempre he tenido ganas de ir a la escuela. Ofelia

Mi mamá quiso... quiso mandarme a otro pueblo... pero ya no aguanté ahí porque extrañaba mi familia, extrañaba a mi mamá con que iba a la milpa, mujum, ya no pude yo vivir porque era ya otro lugar, pues tenía que estar ahí viviendo, dejar mi casa dejar todo y ya no pude, me dio mucha lástima y me daba tristeza de que ya no vaya [sic] a la escuela, tenía yo ganas de seguir. Luz Ma.

Mi papá no me quiso apuntar a la secundaria, dijo que no, que eso era para los hombres, que yo para qué quería estudios si yo iba a que me "mantenieran", no iba a mantener y ya no me dio escuela, ya después yo trabajé y ya después yo me estuve estudiando la secundaria por, por, o sea, por mí. Ofelia 


\section{Autoconcepto}

La autodescripción refleja su identidad: se refieren a sí mismas como inseguras, con mucho miedo y timidez, como la última de la familia: ignorada y no tomada en cuenta; como la que no tenía nada que hacer en su familia. Destaca la autodefinición devaluatoria y con desprecio hacia sí misma: "yo era tonta, muy tonta"

Pues este... pues crecí muy insegura... o sea siempre fui tím... o me daba... todo me daba miedo, timidez, fui muy tímida y sí se siente porque siempre por ejemplo cuando yo estuve más grandecita cinco-seis años, pues empecé a tener amiguitas ahí en la colonia y veía yo cómo eran sus mamás y yo siempre decía: ojalá mi mamá fuera así conmigo. Rosa

Yo pienso que mi lugar es el último ieh?, hasta la fecha, el último, a mí no me toman en cuenta para absolutamente nada, yo ahí para ellos, para ninguno cuento, no sé si por lo mismo de que me ha cambiado el carácter me han hecho a un lado pero desde que me acuerdo siempre ha sido igual. Inés

Crecí desprotegida y abandonada, como un animalito, no me sentía parte de mi familia, siempre estuve desamparada y triste, todos me maltrataban dentro y fuera de mi casa. Eugenia 
Las familias de procedencia de las mujeres entrevistadas, reflejan escenarios inestables, precarios, poco favorables para que las niñas se desarrollaran con sentimientos de valoración hacia sí mismas, hacia sus deseos y necesidades, con la suficiente seguridad y fortaleza interna que les permitiera la posibilidad de tomar decisiones y construir su autonomía, así como el relacionarse en términos de igualdad.

Analizar cómo se construyeron como mujeres, en tanto sujetos de nuestra cultura y el efecto que ello ha tenido sobre su salud, puede hacer posible el entendimiento de la manera en que las condiciones de la vida, en especial de la vida cotidiana, han repercutido de modo decisivo sobre su enfermedad. Esa vida cotidiana tiene como rasgo característico la sedimentación de un conjunto de actividades y actitudes que bajo la forma de rutinas y de hábitos, se mantienen constantes por un periodo prolongado de tiempo.

Las mujeres de este estudio fueron construidas socialmente en una cotidianidad cargada de frustración y violencia, la infancia vivida estableció características en su identidad, que determinaron las acciones y las decisiones relacionadas consigo mismas. Los rasgos que constituyeron su subjetividad fueron la inseguridad, el inmerecimiento, la desvalorización, la necesidad de pertenencia y de aceptación.

\section{Conclusiones}

La cotidianidad en la que se llevó a cabo la infancia de las mujeres entrevistadas, manifiesta los aspectos culturales y socioeconómicos 
de las circunstancias en las que crecieron. La cotidianidad convertida en un estilo de vida que propicia el ambiente para contraer la infección del virus de papiloma humano y desarrollar cáncer cervicouterino: reproducen en sí mismas la forma en que aprendieron que deben verse y tratarse: con pobre o nulo nivel de autocuidados, el cuerpo no se cuida, el cuerpo es para el sobreesfuerzo y el sacrificio; de niñas su cuerpo fue dedicado al trabajo impuesto, vinculado al dolor, a las necesidades físicas y afectivas insatisfechas y a pobres vivencias de bienestar.

La relación con el propio cuerpo tiene que ver con el nivel de conciencia y la capacidad de concebirse a sí misma como dueña de un cuerpo que tiene funciones y que merece atención y cuidados en cuanto a la higiene, la alimentación y la prevención de enfermedades, y de esta manera propiciar, mantener y disfrutar de la salud y del bienestar.

La violencia que sufrieron de niñas se destacó en las historias. Tuvieron una infancia de maltrato y abandono. Crecieron padeciendo violencia física y emocional de una madre violentada por el padre y el medio.

Las niñas fueron sometidas a un nivel muy alto de exigencias, delegaban en ellas responsabilidades y obligaciones que llegaron a la explotación laboral sin escuchar sus sentimientos ni sus deseos, algunas de ellas fueron apartadas de su núcleo familiar para enviarlas a trabajar a otros pueblos, viviendo un desgarramiento afectivo por la separación. Niñas para el trabajo, para los demás. 
Analizando la infancia de estas mujeres desde los factores de riesgo del cáncer cervicouterino, encontramos que se trata de niñas deprimidas por el ambiente familiar depresor en el que crecieron, el papel preponderante de la violencia, la desnutrición propia de la pobreza, el maltrato y la frustración que sistematizaron el dolor y el sufrimiento, han debido generar repercusiones y vulnerabilidad a nivel inmunológico: el campo propicio para las infecciones.

Las mujeres que participaron en este trabajo tuvieron una infancia con una vivencia corporal de devaluación, sus etapas tempranas las colmaron de experiencias que integraron una estructura de personalidad con la autodevaluación como un rasgo primordial, al llegar a la etapa adulta y ser diagnosticadas con cáncer ellas ven confirmada una profecía de fatalidad, se trata de un hecho que confirma un pobre autoconcepto basado en el inmerecimiento que aprendieron de niñas, fueron criadas en el maltrato, aprendieron que su cuerpo no se cuida, no se acaricia, no se alimenta, no se nutre afectivamente. Existe en ellas una mirada a sí mismas de autoconmiseración, se trataron y se cuidaron como se les enseñó que deben ser tratadas y cuidadas.

La indiferencia es una manifestación de violencia en grado extremo, y la padecen estas mujeres durante su infancia, les son subestimados sus escasos logros, se les escatima interés y apoyo. Todo esto lo incorporan en sí mismas para reproducirlo en sus autocuidados: no escuchan los mensajes de su cuerpo, posponen la propia satisfacción y no identifican sus deseos. 
Predomina el silencio en relación a las funciones de su cuerpo: aprenden que sus órganos sexuales son invisibles, innombrables y lo que se siente en ellos no se dice y/o se ignora ya sea dolor o placer. Se aprende a desarrollar culpa y vergüenza hacia los órganos genitales y sus funciones, las características fisiológicas del cuerpo femenino son vividas entre temores, sobresalto y sentimientos de transgresión.

El pobre nivel de merecimiento con el que aprendieron a tratarse se va identificando en el curso de sus historias: inevitablemente vinculan el placer con la culpa, pero no sólo el placer a nivel sexual, a todos los niveles ellas se postergan, aprendieron de niñas que sus deseos y necesidades eran aplazables, subordinadas a las exigencias familiares, no hubo cabida a la adquisición de autonomía y asertividad, no detectan, no identifican sus anhelos o sus ideales, ni siquiera consideran que tienen el derecho a establecerlos.

"No merezco atención", "no valgo para nadie", "no puedo hacer nada", "mis deseos no importan", son mensajes que las mujeres participantes recibieron y los convirtieron en realidad en sí mismas: la autopostergación y la autorrenuncia, ante los estudios de prevención o detección oportuna: el Papanicolaou y/o la colposcopia, que de las quince mujeres entrevistadas nueve nunca se lo realizó; tres mujeres se hicieron uno en toda su vida; cada dos o tres años se lo hicieron dos mujeres y una mujer se lo hizo cada cuatro o cinco años. Conducta que pone de manifiesto la falta de asertividad e indefensión aprendida en el enfermar de estas mujeres. 
La ideología transmitida a las informantes reproduce en ellas el modelo femenino con características de sacrificio, autopostergación y autorrenuncia. Se desarrolla una identidad con rasgos de inseguridad y de pobre autoestima, carente de asertividad, falta de autonomía y con escaso control de la propia vida.

La forma en la que se definen a sí mismas contiene dolor, rechazo, inmerecimiento, devaluación, necesidad de ser aceptada y acariciada.

El cáncer cervicouterino es una enfermedad del poder, que a través de la trasmisión ideológica forma mujeres enfermables. Se les ha declarado seres para los otros. La sociedad y la cultura hacen de las mujeres seres que aman a los otros y en este mandato está la negación del amor a sí mismas.

El trabajo se realizó con un grupo de quince mujeres pertenecientes a un nivel socioeconómico y educativo bajo. Como una propuesta ante los resultados expuestos, se podría plantear la realización de este tipo de estudio con mujeres del mismo estrato social que no desarrollaron cáncer cervicouterino y comparar la trasmisión ideológica en cuanto a los modos de enfermar, o bien, realizarlo con mujeres con cáncer cervicouterino de niveles sociales más altos.

\section{Bibliografía}

ABELIN SAS, Graciela. "La Leyenda de Schehrezade en la vida cotidiana”, en Burin Mabel y Dio Bleichmar Emilce Género, psicoanálisis, subjetividad. Argentina: Paidós, 1999. 
Aguado, V. J. C. Cuerpo Humano e Imagen Corporal. Notas para una Antropología de la Corporeidad. México: UNAM, Instituto de Investigaciones Antropológicas, 2004.

Aisenson, K. A. Cuerpo y Persona. Filosofía y Psicología del Cuerpo Vivido. México: Fondo de Cultura Económica, 1981.

AlLEN, Betania. Una exploración de los vínculos entre el cáncer cervicouterino y la sexualidad de las mujeres, en Cáncer Cervicouterino, Edit. Ma. del Carmen Elú. México: Comité Promotor por una Maternidad sin Riesgos en México, 1998.

Aulagnier, Piera. "Nacimiento de un cuerpo, origen de una historia", en Cuerpo, historia e interpretación, de lo originario al proyecto identificatorio. México: Paidós, 1991.

Bernard, Michel. El Cuerpo, un fenómeno ambivalente. Barcelona: Paidós, 1994.

BuRIN, Mabel. "Ámbito Familiar y Construcción del Género”, en Género y familia. Poder, amor y sexualidad en la construcción de la subjetividad. Argentina: Paidós, 2001.

— y Meler, Irene. Género y familia. Poder, amor y sexualidad en la construcción de la subjetividad. Argentina: Paidós, 2001.

Careaga, Gloria y Guevara Elsa. "Género y cáncer cervicouterino”, en Cáncer Cervico Uterino, Edit. Ma. del Carmen Elú. México: Comité Promotor por una maternidad sin riesgos en México, 1998.

De los Ríos, Rebecca. "Género, salud y desarrollo”, en Gómez Gómez Elsa, Género, mujer y salud en las Américas. Organización Panamericana de la Salud, 1993. 
Dejours, Christophe. Investigaciones Psicoanalíticas sobre el Cuerpo. México: Siglo XXI, 1992.

ERIKSON, Erick H. Identidad, juventud y crisis. Argentina: Paidós, 1978.

FERNÁNDEZ, Ana Ma. La mujer de la ilusión. Pactos y contratos entre hombres y mujeres. Argentina: Paidós, 1993.

—. Las mujeres en la imaginación colectiva. Una historia de discriminación y resistencias. Argentina: Paidós, 1992.

Fernández Rivas, Lidia y Ruíz Velasco, Ma. Eugenia. Las cicatrices del cuerpo, en cuerpo, significaciones e imaginarios. México: UAM-Unidad Xochimilco, 1999.

Gómez GómEz, Elsa. Género, mujer y salud en las Américas. Organización Panamericana de la Salud, 1993.

GonZÁlez de Chávez, Ma. Asunción. Cuerpo y subjetividad femenina. España: Siglo XXI, 1993.

Hidalgo Martínez, Ana C. El cáncer cervicouterino, su impacto en México y el por qué no funciona el programa nacional de detección oportuna. Revista Biomed, 17: 81-84 Vol. 17/ No.1/ enero-marzo, 2006.

IsLAS, H. De la historia al cuerpo y del cuerpo a la danza. México: INBA/ CONACULTA, 2001.

LAGARDE, Marcela. Ser mujer, un riesgo para la salud. México: Edición Ana Victoria Jiménez A. Red de Mujeres, 1997.

LAmAs, Martha. El Género: La Construcción Cultural de la Diferencia Sexual, Programa Universitario de Estudios de Género, UNAM. México: Porrúa, 1996.

LAQUEUR, Thomas. La construcción del sexo, cuerpo y género desde los griegos hasta Freud. España: Cátedra, 1994. 
LAU JaIVEN, Ana. La historia oral: una alternativa para estudiar a las mujeres. México: Instituto Mora, 1994.

. "Cuando hablan las mujeres", en Debates en Torno a una Metodología Feminista. Bartra, E., comp. Programa Universitario de Estudios de Género, UnAM. México: Universidad Autónoma Metropolitana, 2002.

LeONelli, Leslie E. Más allá de los labios. Barcelona: Noguer, 1995.

López, Ma. de la Paz y SAlles, Vania. Familia, género y pobreza. México: Porrúa, 2000.

Restrepo, Helena E. "Epidemiología y control del cáncer de la mujer en América Latina y el Caribe”, en Género, Mujer y Salud. Organización Panamericana de la Salud. Washington: Edit. Elsa Gómez Gómez, 1993.

Ricoeur, Paul. Ideología y Utopía. Barcelona: Gedisa, 1991.

SCHILDER, Paul, Imagen y apariencia del cuerpo humano. Estudios sobre las energías constructivas de la psique. México: Paidós, 1989.

TORRES LOBATÓN, Alfonso et al. Exenteraciones pélvicas por cáncer cervicouterino (factores pronóstico) Ginecol Obstet Mex; 78(11): 598 604 Volumen 78, num.11, noviembre, 2010.

WeEKS, Jeffrey. El malestar de la sexualidad. Significados, mitos y sexualidades modernas. Madrid: Talasa, 1993.

. Sexualidad. México: Paidós/Pueg/unam, 1998.

. "Los valores y el colapso de las certidumbres morales", en Letra S, La Jornada, 2 de marzo de 2000, México. 